\section{RMD Open}

Rheumatic \&

Musculoskeletal Diseases

\title{
Antirheumatic drugs for cardiovascular disease prevention: the case for colchicine
}

\author{
Willem Lems (D) , ${ }^{1,2}$ Maarten Boers (D) , ${ }^{3}$ Ronald F van Vollenhoven (D) , \\ Mike Nurmohamed ${ }^{1}$
}

To cite: Lems W, Boers M, van Vollenhoven RF, et al. Antirheumatic drugs for cardiovascular disease prevention: the case for colchicine. RMD Open 2021;7:e001560. doi:10.1136/ rmdopen-2020-001560

Received 24 December 2020 Revised 4 March 2021 Accepted 5 March 2021
Check for updates

(C) Author(s) (or their employer(s)) 2021. Re-use permitted under CC BY-NC. No commercial re-use. See rights and permissions. Published by BMJ.

${ }^{1}$ Rheumatology, Amsterdam Rheumatology and Immunology Center, Amsterdam, NoordHolland, The Netherlands 2Department of Rheumatology, Reade, Amsterdam, NoordHolland, The Netherlands ${ }^{3}$ Department of Epidemiology and Biostatistics, VU University Medical Centre, Amsterdam, Noord-Holland, The Netherlands

Correspondence to Professor Willem Lems; wf.lems@amsterdamumc.nl

\section{ABSTRACT}

We summarised four pivotal Randomised Controlled Trials (RCTs) with antirheumatic drugs on the secondary prevention of cardiovascular events. The favourable effects of canakinumab and colchicine confirm (lowgrade) inflammation as an independent risk factor for cardiovascular events. While colchicine might be the first drug in the clinic, we expect that this is only the first in a future series of anti-inflammatory drugs used in secondary prevention of cardiovascular events.

Chronic inflammation is a key driver in the development of atherosclerotic cardiovascular disease. Proinflammatory mediators such as TNF $\alpha$ and IL-1 $\beta$ are important in the development of dysfunctional endothelium, the first step of atherogenesis. The next step is subendothelial monocyte infiltration where accumulated LDL cholesterol is oxidised leading to atherosclerotic plaque formation. ${ }^{1}$ Plaques rupture or develop superficial erosions, causing thrombosis and cardiovascular events. $^{2}$

The important proinflammatory cytokine IL-1 $\beta$ is generated after proteolytic cleavage of pro-IL-1 $\beta$ by caspase- 1 that in turn is activated by the nucleotide-binding oligomerisation domain-containing, leucinerich repeat-containing and pyrin domaincontaining protein 3 (NLRP3) inflammasome. Uric acid crystals as well as cholesterol crystals initiate inflammation by complement activation. $\mathrm{C} 3 \mathrm{~b}$ then activates macrophages to produce the NLRP3 inflammasome.

Methotrexate (MTX) significantly reduces the cardiovascular disease risk in rheumatoid arthritis (RA) by favourable effects on vascular function and blood pressure. ${ }^{3}$ The precise underlying mechanisms are not known but are thought to be related with targeting specific inflammatory pathways, particularly the effects on $5^{\prime}$ adenosine monophosphate-activated protein kinase seem to be pivotal. ${ }^{4}$

Recognition of the important role of inflammation in atherogenesis led to trials, in non-arthritis patients, with several antiinflammatory drugs, that is, canakinumab, MTX and colchicine, to study their potential for secondary prevention of cardiovascular events in patients with established cardiovascular disease.

Two agents target the IL-1 $\beta$ pathway: Canakinumab, an expensive monoclonal antibody, directly inhibits this cytokine; in Europe, it is approved for patients with refractory gout, cryopyrin-associated periodic fever syndromes and Still's disease. Colchicine is a very old and cheap drug that decreases production of IL-1 $\beta$ and other pro-inflammatory cytokines through inhibition of the formation of the NLPR3 inflammasome. Recently, four pivotal RCT's with these two agents have been published.

The first study (from 2017) compared three different dosages of canakinumab (50 $\mathrm{mg}, 150 \mathrm{mg}$ and $300 \mathrm{mg}$ given subcutaneously) versus placebo in 10.061 patients with a history of myocardial infarction and a highsensitive $\mathrm{C}$ reactive protein level of $\geq 2 \mathrm{mg} / \mathrm{L}^{5}$ The primary endpoint was a composite index of non-fatal myocardial infarction, non-fatal stroke and cardiovascular death: after a mean follow-up of 3.7 years, a statistically significant decrease was found in the $150 \mathrm{mg}$ group (HR 0.85 , with $95 \%$ CI:

0.74 to $0.98, \mathrm{p}=0.021)$ and in the 300 $\mathrm{mg}$ group (HR 0.86, 95\% CI: 0.75 to $0.99, \mathrm{p}=0.031)$. Thus, this landmark study demonstrated for the first time that an antiinflammatory drug could reduce the occurrence of cardiovascular events in patients with a previous myocardial infarction. However, the higher incidence of fatal infections and the (current) prohibitively high drug costs 
disqualifies this drug for widespread use in secondary cardiovascular prevention.

Therefore, the Cardiovascular Inflammation Reduction Trial (CIRT) study from 2019 on the effects of MTX for the secondary prevention of atherosclerotic events in patients with previous myocardial infarction or multivessel coronary disease is of interest. ${ }^{6}$ MTX is an inexpensive antirheumatic drug, widely recommended as first-line choice for RA. ${ }^{78}$ Unfortunately, the result of the study in 4786 patients comparing MTX $15-20 \mathrm{mg}$ /week or placebo over 2.3 years was negative: the HR for the primary endpoint was 1.01, 95\% CI: 0.82 to 1.25 . CRP levels did not decrease during the study, probably related to the low CRP levels at baseline, $1.5 \mathrm{mg} / \mathrm{L}$. For comparison, the mean CRP level at baseline in the canakinumab study (ref) was $4.2 \mathrm{mg} / \mathrm{L}$ and decreased $40 \%$ during the study.

Remarkably, serum levels of IL-1 $\beta$ and IL- 6 also did not decrease in CIRT, which suggests that MTX in this population did not target these critical cytokines.

However, in patients with inflammatory conditions, such as RA, the results can be different: Roubille et al showed a 28\% reduction in cardiovascular events in MTX users. $^{9}$

The Colchicine Cardiovascular Outcomes Trial study, published in 2019, randomised 4745 patients with a recent myocardial infarction to colchicine $0.5 \mathrm{mg}$ /day or placebo, in addition to their cardiovascular medication. ${ }^{10}$ The primary endpoint was a composite index of cardiovascular death, resuscitated cardiac arrest, myocardial infarction, stroke or urgent hospitalisation for angina leading to coronary revascularisation. This endpoint was met in 5.5\% of colchicine-treated patients and in $7.7 \%$ of the placebo group (HR 0.77, 95\% CI: 0.61 to 0.96 , $\mathrm{p}=0.02)$. However, this difference was based on a $50 \%$ reduction in angina leading to revascularisation and $75 \%$ reduction in stroke, without significant reduction in the other three endpoints. Therefore, the results were criticised in that the benefit was modest and driven by the soft endpoint of angina for revascularisation and thus did not support routine use of colchicine without a better understanding on the absence of effect on myocardial infarct and death. ${ }^{11}$

What about the side effects? Diarrhoea was found in similar proportions, $9.7 \%$ (colchicine) versus $8.9 \%$ (placebo), $\mathrm{p}=0.35$, probably related to the low dosage of colchicine. Somewhat unexpectedly, pneumonia occurred more often in colchicine users $(0.9 \%$ vs $0.5 \%, \mathrm{p}=0.03)$. Another remarkable point is that statins were used in $94 \%$ of patients, but myalgias, regarded as a common side effect, occurred only slightly more frequently in colchicine users: $21.2 \%$ versus $18.5 \%$.

Recently, Nidorf et al published a study (low dose colchcine (LoDoCo2)) that randomised 5522 patients to colchicine $0.5 \mathrm{mg} /$ day or placebo. ${ }^{12}$ Only patients with chronic coronary disease were included, $84 \%$ had a previous acute coronary syndrome. After a median follow-up of 29 months, the primary endpoint (cardiovascular death, myocardial infarction, ischaemic stroke or ischaemicdriven coronary revascularisation) was met in $6.8 \%$ of the colchicine group and in $9.6 \%$ of the placebo group: (HR $0.69,95 \%$ CI: 0.57 to $0.83, \mathrm{p}=0.001$ ). In addition, favourable (non-significant) trends were seen for cardiovascular death (20 in colchicine-treated patients vs 25 in placebo) but not for non-cardiovascular death (53 vs 35 , respectively).

Very recently, in an interesting but relatively small Australian randomised controlled study (COPS) in 795 patients with an acute coronary syndrome, 24 cardiovascular events were observed in the colchicine group and 38 in the placebo group $(\mathrm{p}=0.09)$, although that there was an increased risk in non-cardiovascular death in the colchicine group ( 5 vs $0, p=0.024$ ). ${ }^{13}$ It is possible that the imbalance in non-cardiovascular death was related to chance, in the COPS trial $3 / 5$ non-cardiovascular deaths occurred in patients who ceased colchicine early ( $<30$ days) and died months later. In the LoDoCo2 trial, a favourable trend was seen for cardiovascular death in the colchicine group: as a consequence, the risk of non-cardiovascular death was higher in the placebo group. In meta-analyses, no significant increase in noncardiovascular death was found. ${ }^{14} 15$ That is reassuring, but further research on this topic should be on the research agenda.

\section{WHAT CAN WE LEARN FROM THESE TRIALS?}

The favourable results for canakinumab and colchicine confirm (low-grade) inflammation as an independent risk factor for cardiovascular events and a new opportunity for treatment. The negative results in the MTX study do not detract from this, as the levels of CRP, IL-1 $\beta$ and IL-6 did not decrease during MTX treatment.

In addition, the large number of included patients yield important information on side effects: cancers, particularly non-basal cell skin cancers, occurred more often in the MTX group; ${ }^{16}$ the sample size of this study exceeds previous RCTs within the field of rheumatology with MTX. Remarkably, the occurrence of myalgias did not differ significantly between colchicine and placebo users. Whether or not colchicine leads to an increased risk of non-cardiovascular death needs to be elucidated.

The data on the favourable cardiovascular effects and safety of colchicine are convincing, and the drug costs are low. Moreover, all rheumatologists have experience in the long-term use with this drug and side effects are usually mild and rare ${ }^{17}$ although colchicine must not be described in patients with advanced renal disease and might be limited by leucopenia and polyneuropathy. Perhaps the most burning question is: how to implement the findings of these studies? We have several recommendations:

First, we believe that cardiologists are not (yet) used to prescribe anti-inflammatory drugs for secondary prevention of cardiovascular events and may be somewhat reluctant to do that. Thus, our first-line action should be to 
initiate contact between the rheumatologist and the cardiologist and to discuss whether the additional use of an anti-inflammatory drug such as colchicine is an option in patients at high risk for secondary cardiovascular events.

Second, we also feel that national organisations of rheumatology should start forging bridges with national organisations of cardiology to help to implement the use of anti-inflammatory drugs for the secondary prevention of cardiovascular events in patients with atherosclerosis. The same applies to our larger organisations, such as EULAR, ACR and ILAR.

Third, the recent convincingly positive results lead to many follow-up questions on the research agenda: is the benefit seen with colchicine and canakinumab in secondary prevention also applicable in primary prevention? As rheumatologists, we would be inclining this first and foremost in patients with inflammatory rheumatological diseases.

Fourth, for the academic rheumatologist, these findings point to many important avenues for future research. Studies of these mechanisms have been boosted by the availability of successful treatments, and we anticipate that the demonstrated clinical benefit of IL-1 blockade will refine our understanding of the role of this cytokine in atherogenesis and that of future successful treatments in this arena.

In summary, we are convinced that the use of antiinflammatory and immunomodulatory medications is now becoming a reality for the secondary prevention of cardiovascular events, with colchicine as the first drug in the clinic, but with the expectation that hopefully this is only the first in a future series of anti-inflammatory drugs. As rheumatologists, being experts on the use of these medications, we should embrace a new role in extending their potential benefits to millions of individuals.

Contributors WL initiated the manuscript and selected the studies on antiinflammatory drugs and cardiovascular endpoints. MN delivered the first part on atherosclerosis as an inflammatory process and critically revised the manuscript. $\mathrm{MB}$ and RFvV critically revised the manuscript and added valuable thoughts about the implementation. All authors approved the manuscript.

Funding The authors have not declared a specific grant for this research from any funding agency in the public, commercial or not-for-profit sectors.

Competing interests WL: received fees for lectures and advisory boards from Amgen, Eli Lilly, UCB, Pfizer, Galapagos and Curaphar. RFvV: research support (institutional grants): BMS, GSK, Lilly and UCB; support for educational programs (institutional grants): Pfizer and Roche; consultancy, for which institutional and/or personal honoraria were received: AbbVie, AstraZeneca, Biogen, Biotest, Celgene, Galapagos, Gilead, Janssen, Pfizer, Sanofi, Servier and UCB and speaker, for which institutional and/or personal honoraria were received: AbbVie, Galapagos, Janssen, Pfizer and UCB. MN: consulting fees from AbbVie, Celgene, Celltrion, Eli Lilly, Janssen and Sanofi, speaker's fees from AbbVie, Bristol-Myers Squibb, Eli Lilly, Roche and Sanofi and research funding from AbbVie, Bristol-Myers Squibb, Celgene, Eli Lilly, Janssen, MSD, Mundipharma, Novartis, Pfizer, Roche and Sanofi.
Patient consent for publication Not required.

Provenance and peer review Not commissioned; externally peer reviewed.

Data availability statement Data are available in a public, open access repository.

Open access This is an open access article distributed in accordance with the Creative Commons Attribution Non Commercial (CC BY-NC 4.0) license, which permits others to distribute, remix, adapt, build upon this work non-commercially, and license their derivative works on different terms, provided the original work is properly cited, appropriate credit is given, any changes made indicated, and the use is non-commercial. See: http://creativecommons.org/licenses/by-nc/4.0/.

\section{ORCID iDs}

Willem Lems http://orcid.org/0000-0002-6885-3953

Maarten Boers http://orcid.org/0000-0002-6969-283X

Ronald F van Vollenhoven http://orcid.org/0000-0001-6438-8663

\section{REFERENCES}

1 Kattoor AJ, Pothineni NVK, Palagiri D, et al. Oxidative stress in atherosclerosis. Curr Atheroscler Rep 2017;19:42.

2 Vergallo R, Crea F. Atherosclerotic plaque healing. N Engl J Med Overseas Ed 2020;383:846-57.

3 Hansildaar R, Vedder D, Baniaamam M, et al. Cardiovascular risk in inflammatory arthritis: rheumatoid arthritis and gout. Lancet Rheumatol 2021;3:e58-70.

4 Mangoni AA, Zinellu A, Sotgia S, et al. Protective effects of methotrexate against proatherosclerotic cytokines: a review of the evidence. Mediators Inflamm 2017;2017:1-11.

5 Ridker PM, Everett BM, Thuren T, et al. Antiinflammatory therapy with canakinumab for atherosclerotic disease. N Engl J Med 2017;377:1119-31

6 Ridker PM, Everett BM, Pradhan A, et al. Low-Dose methotrexate for the prevention of atherosclerotic events. N Engl J Med 2019;380:752-62.

7 Smolen JS, Landewé RBM, Bijlsma JWJ, et al. EULAR recommendations for the management of rheumatoid arthritis with synthetic and biological disease-modifying antirheumatic drugs: 2019 update. Ann Rheum Dis 2020;79:685-99.

8 Singh JA, Saag KG, Bridges SL, et al. 2015 American College of rheumatology guideline for the treatment of rheumatoid arthritis. Arthritis Rheumatol 2016;68:1-26.

9 Roubille C, Richer V, Starnino T, et al. The effects of tumour necrosis factor inhibitors, methotrexate, non-steroidal anti-inflammatory drugs and corticosteroids on cardiovascular events in rheumatoid arthritis, psoriasis and psoriatic arthritis: a systematic review and meta-analysis. Ann Rheum Dis 2015;74:480-9.

10 Tardif J-C, Kouz S, Waters DD, et al. Efficacy and safety of low-dose colchicine after myocardial infarction. $N$ Engl J Med 2019;381:2497-505.

11 Newby LK. Inflammation as a treatment target after acute myocardial infarction. N Engl J Med 2019;381:2562-3.

12 Nidorf SM, Fiolet ATL, Mosterd A, et al. Colchicine in patients with chronic coronary disease. N Engl J Med 2020;383:1838-47.

13 Tong DC, Quinn S, Nasis A, et al. Colchicine in patients with acute coronary syndrome: the Australian cops randomized clinical trial. Circulation 2020;142:1890-900.

14 Samuel M, Tardif J-C, Bouabdallaoui N, et al. Colchicine for secondary prevention of cardiovascular disease: a systematic review and meta-analysis of randomized controlled trials. Can J Cardiol 2020;S0828-282X:31053-9.

15 Xia M, Yang X, Qian C. Meta-Analysis evaluating the utility of colchicine in secondary prevention of coronary artery disease. Am J Cardiol 2021;140:33-8.

16 van Vollenhoven RF, Nurmohamed M. Methotrexate for prevention of cardiovascular events. N Engl J Med 2019;380:2276-76.

17 Stewart S, Yang KCK, Atkins K, et al. Adverse events during oral colchicine use: a systematic review and meta-analysis of randomised controlled trials. Arthritis Res Ther 2020;22:28. 